\title{
Effect of Social Media on Marketing
}

\begin{abstract}
Lanlin Zhao
Business Analysis \& Modern Marketing, Ohio State University, USA

zhaolanlin1102@gmail.com

ABSTRACT

The growing popularity of social media enables the development of marketing. Primarily, social media is an interactive platform where people can exchange information concerning various professional fields. The platforms mainly depend on phone applications that people use to share information, especially in business entities. Today, social media users exceed even the population of countries. By comparing the marketing before and after social media introduction, technologies used to impact marketing through social media come to light. Social media enables interaction among business associates and customers within the field of marketing. Primarily, marketing is all about business research, planning, executing, and promoting goods and services. Consequently, social media enables the creation of content and participation in social networking. Meanwhile, the media is mainly accessible to the public and allows bi-directional communication. Social media impacts brand awareness, profits, brand loyalty, customer service, and competition.
\end{abstract}

Keywords:social media, social network, marketing, customer service, profit

\section{INTRODUCTION}

Social media allows consumers to recognize and appreciate various brands. The positive image of a product helps in marketing activities. Through social media advertisements, consumers become aware of various brands in the market. Social media help build brand awareness because it holds a ton of people in one platform; thus, allowing marketers to meet more people through the Internet [1]. For example, Hootsuite conducted a study to investigate the population using the Internet in 2018 [2]. The number of social media users was approximately 4 billion, which is higher than in previous years [2]. However, the fact is that not all people on the Internet use social media. According to Statista, the steady increase in social media use could lead to more people accessing the platforms. In profundity, the number of social media users in 2021 rises to over 3 billion [2]. Many marketers reveal that using social media increase brand awareness for their products. In this context, marketers increase brand awareness by primarily aiming to improve community engagement and increase web traffic. Further, marketers define social media engagement through likes and comments, share or retweets, revenue attribution, and consumer interaction. However, 72 percent of markets rely on likes and comments to define the level of their brand awareness [2]. Therefore, the likes and comments on Facebook and
Twitter allow marketers to measure brand awareness while focusing on revenue attribution.

Alternatively, marketers use social media platforms to promote their social strategy. Brand's messaging relates to the target audience available within every social media platform. The major platforms used include Facebook, Instagram, Twitter, and YouTube. For instance, 89 percent choose Facebook as their favorite social media platform to showcase their products, but only 66 percent of consumers follow the brands on Facebook [2]. Marketers try to reach as many consumers as possible to develop a sense of quality brands. Also, Instagram enables marketers to incorporate an imagesharing strategy since it comprises a high number of influencers. Accordingly, brands have various options for increasing consumer engagement. The ability to include convert social media users to consumers facilitates marketing. Marketers enable engagements in social media through conversation and the creation of advertisements [3]. Importantly, social media platforms comprise potential customers, existing customers, and new people. Therefore, the platforms offer a dynamic market where consumers can find their preferred brands or contact the sellers.

Further, content creation arises through the use of social media. Various companies share information about their brands on social media platforms to push their blogs, videos, and other content that seems persuasive to 
the consumers [3]. Specifically, marketers share their content if their following like to research the usefulness of the brands. Sharing the content allows a wider reach to consumers since interested people can also find it meaningful and share it through their social media accounts. In other words, sharing content can allow the building of brand awareness through social media platforms.

Accordingly, social sharing is vital since it impacts the brand, mainly through the ability to extend its reach when marketers create something shareworthy. A good example is Wendy's comeback on her Twitter account. Primarily, Wendy's tweets caused fan uproar via retweets since they found the information funny. Accordingly, creating something appealing to the public allows them to develop an emotional attachment and believe in it; thus, many social media users can share them [4]. The concept is to attract the attention of people using something funny but relevant to promote marketing. Marketers can adopt the strategy used by Wendy on her Twitter account to increase consumer reach on their brands. The social share buttons serve the purpose of reaching out to people within a specific social media platform. For example, an e-Commerce store website uses social media share buttons to enhance insightful content and sharing of information [1]. Therefore, the component of social media allows marketers to interact with their potential consumers while increasing brand awareness by sharing funny stories about the products.

\section{WEBSITE VISIT TRAFFIC EFFECT ON PROFITS}

With the advancing digital technology, social media networks have become the best strategy for businesses aiming for digital marketing and the maximization of profits. Online retailers use social media daily to carry out their sales. The business outcomes of online retailers depend on website visit traffic, orders, and sales. Social media enhances web traffic but does not influence sales income. The most productive social media platform is Facebook, which incorporates campaigns that tend to increase the number of orders and sales income for businesses and companies [5]. However, the nature of social media markets depends on the products' complexity, cost, and brand status. Accordingly, social media serves as a leeway to increase web traffic and determine the profitability of a business. Hence, social networks convert their users to followers of brands.

Similarly, the success of an online retail business is measured through returning direct visitors, new direct visitors, returning organic visitors, new organic visitors, new social visitors, and returning social visitors [6]. The page views per visit account for the level of web traffic. Notably, social media offers a bridge towards web traffic because marketers can create website links through their social media account to redirect the consumer to their catalog [7]. The ease in finding companies' catalogs allows consumers to purchase goods directly from them. Besides, people can take time to read through the content of the websites. Therefore, high web traffic leads to an increase in profits for the business and the overall revenue collection.

Social media platforms also promote blogs, videos, and other content related to company products. Since the number of people using the platforms in the world is too high, many companies sell their products or services through the platforms. The traffic evident on websites arises from social networks. According to Travelpayouts (2021), companies gain web traffic from social media through paid, free, and mixed methods [5]. First, the consumer can buy a product from Facebook Ads or contact the owner through social accounts. Second, a marketer can build and develop a website to gain traffic from social networks. When attracting social media users to the website, marketers can increase their revenues through advertisements from social networks. Specifically, companies usually post their ads on social networks but include their website links so that the consumers can analyze the products before making purchases [5]. The role of social networks is to act as an intermediary between the consumers and the website containing the catalog. Therefore, an increase in website visit traffic signifies an increase in sales and orders, leading to profitability.

In the real sense, the number of profits relates to the optimizing search engines used in the respective company websites carrying out e-Commerce sales. For a website to have high traffic, it must record a high rate of visits. Search Engine Optimization (SEO) plays a role in justifying the potential impact of social networks on the popularity of many businesses. Since Google has more than 35 trillion searches, companies need to optimize search engines on their websites to have them on the top searchers [7]. Therefore, people can reach the website through social media, but it does not appear at the top of the Google search list. In this case, social networks cannot offer substantive profits through the website. Therefore, social networks work hand in hand with optimizing search engines to boost web traffic.

\section{KEEPING BRAND LOYALTY THROUGH SOCIAL MEDIA ACCOUNT}

For effective social media marketing, marketers need to be loyal to their followers. Brand loyalty matters since it ensures long-term engagement on social media accounts. The number of followers of a social media account signifies the brand's popularity; thus, loyal followers add the brand's value and convince potential consumers to purchase the products [8]. Marketers embrace brand loyalty in social platforms by embracing their advertising and sales strategies since they have unique opportunities and intricacies. Social media not 
only offers room for posting and interaction but allows advertising, marketing, and support within one platform. Additionally, people can view Facebook pages of their interest to consult on the products offered. The large population existing in platforms like Facebook and Instagram unites marketers and consumers globally, thus reducing the distance between them. Due to the competition marketers face on social media, marketers develop a digital marketing strategy that embarks a unified SEO [8]. Social media allows marketers to interact with the consumer at any time; therefore, marketers develop the value that conforms to their brand. Therefore, the development of value guarantees loyalty for the consumers.

Social media platforms allow marketers to create an advertisement using infographics, short videos, graphs, and visual aids to make their content outstanding and notable [4]. Besides, the adverts contain a logo and allow users to apply their preferred color to remain relevant. In other words, social media account includes all details of a business or company offering sale services. Besides, platforms such as Facebook has pages section where companies can showcase their products and indicate their geographical location to allow other users to interact with them. Including contact details such as email addresses on social media accounts promotes brand loyalty. Marketers can promote their membership within the fan pages through quick and accurate responses to Facebook comments and messages [9]. The followers have the opportunity to contact the companies through their Facebook pages. Social media enhances the memorable experience with various brands; thus, social accounts help escalate through the market dynamics. Therefore, social media platforms bring the sellers and buyers close so that they promote marketing.

Ostensibly, advantageous campaigns and the popularity of content on social media networks promote brand loyalty. People use entertaining information on social media to share information about their products. Since interaction is the primary goal of social networks, marketers develop ads to enhance brand loyalty and attract new consumers. The sharing of information is crucial for engaging social media users. Facebook accounts receive likes, comments, and shares from posts that seem reliable and memorable. Consequently, social media has a section for leaving reviews for customers to leave feedback about their perception of the products [10]. Companies can respond to the customer's reviews; thus, allowing the customers to be part of the brand. In this context, the concept of customer review helps develop quality products and services while guaranteeing a sense of inclusion for the customers. According to Forbes, 62 percent of millennials respond that brand engagement encourages them to be loyal customers of respective brands [10]. Thus companies strive to connect with social media users to gather reviews about the products.

\section{CUSTOMER SERVICE WITH GOOD SOCIAL MEDIA RUNNING}

Implementing social media strategy in a customer service model allows customers to communicate with them while encouraging them to recommend a specific brand to others. Comprehensively, marketers ensure social media customer services by activating communication channels, building employee value and trust, and sharing feedback[11]. Facebook users use pages and Messenger to communicate with their customers. Loyalty is built through conversation; thus, companies can use their social media accounts to respond quickly to show their accountability and professional service. Responding to comments and tweets may be helpful to the inquirer and other people interested in the topic [11]. Social networking platforms require engagement in discussions to increase sales. According to Statista, $47 \%$ of United States consumers consider brands that respond to social media complaints [12]. Besides, companies responding fast to customers' complaints are likely to receive shout-outs, practically serving as a free advertisement. With better customer service, companies develop a sense of customer loyalty and promote customer care.

The best way to enable customer service on social media is to be consistent, creative, funny on the posts and tweets. Social media reputation can adopt a roasting strategy to engage the social media users. Twitter allows a messaging ecosystem that people can react towards a certain hashtag to make a topic popular. A good example is Wendy's creation of "beef" with other companies in a sarcastic manner to engage Twitter users [13]. Since Wendy's is a hamburger company, the team uses funny roasting tweets to engage consumers and competitors. In other words, the company provides that the consumers are interested in listening to while embracing a culture of suppressing other brands. The humorous tweets can help various marketers reach out to many consumers. Accordingly, customers usually want what is sizzling and enthusiastic. Also, responding to significant retweets on Twitter signifies concern of customer feedback by the companies. Using a Twitter account for marketing requires marketers to tweet on informative matters so that consumers can comprehend their consistency [11]. Therefore, customer service in social media depends on how companies create their ads and blogs.

In some social accounts, people use chatbots and automated replies and signatures to provide other contacting details or inform the customers on what to do. The automated replies are primarily sent to the customers, indicating customer service hours, phone numbers, links to business websites, email addresses, and the option of live chat. For example, Warby Parker provides customers with multiple solutions when they retweet their tweets asking where to repair glasses [14]. Since many people rely on social media to seek support 
from various companies, companies can implement the platforms to ensure timely responses for the customers. Notably, responses to customers via social media accounts should take 24 hours to encourage their engagement on the company's page [14]. The advantage of social media customer service is the connection to all customers regardless of their geographical location. People can receive feedback any time of the day believing that the products or services sold are of quality standards.

\section{COMPETITION FOR AUDIENCE AND SOCIAL MEDIA ATTENTION-GRABBING}

The increasing number of social media users forces marketers to compete for audiences or followers and focus on attention-grabbing. Since the platforms have target customers, marketers struggle to grab as many followers as possible to promote their product engagement. The world is advancing in an onlineoriented direction so, companies and organization have changed their marketing segmentation to focus on social media customers, who are in millions of numbers [15]. In recent years, social media networks' dominance allows companies to showcase their brand through tweets, visual aids, and posts. With competition, companies encourage innovation to have quality products and services. The marketing field receives pressure from social media users because a significant percentage are free to leave reviews about the brands offered to the public [15]. Primarily, Social media accounts with many followers signify that they can better reach the target audience. Seemingly, celebrities such as Cristiano Ronaldo, who has the largest number of the world's followers, can use his Instagram to advertise a specific company's product to gain more sales. Therefore, the notion is to have as many followers as possible to receive more revenue.

In marketing, social media helps grab the attention of people who might be interested in a product. As part of the promotion outlet, social media facilitates usergenerated content to establish an organization's competitive edge [16]. Accordingly, social media platforms need optimization to gather information from the customers while enhancing networking. A company maintains or raises its competitive edge when they carry out better social media marketing. In other words, the competition edge depends on how the company engages the customers in social media. However, companies selling the same products may start online violence resulting from users' comments [16]. For example, Twitter users involved themselves in creating contradicting hashtags to roast some brands. Even though marketers should treat all public reviews as positive, some can take the comments as negative. Therefore, social media users can affect the competitive edge of some companies since the perception reaches a vast audience.
Further, new products in the market can face criticism when advertised through social media platforms. The aggressions and hate speech that arises on the Internet may derail the performance of a brand. Consequently, the aggressions favor already established companies while demoralizing the development of new brands. Despite the aggression coming from two or three users, the comments might spread to a million of the users; thus, creating a sense of poor quality even before the release of a product into the market [17]. Social media marketing can generally lead to both healthy and unfair competition if embraced by marketers from all companies. Therefore, businesses introducing new products to the market can receive negative reviews; thus, deteriorating their brand.

\section{CONCLUSION}

Overall, social media marketing impacts brand awareness, profits, brand loyalty, customer service, and competition. With the increase of social media users, companies rely on platforms to improve their brands and attract more customers. In marketing, social media is a promotional tool to enhance brand awareness and improve an organization's competitive edge. For Twitter and Facebook users, marketers depend on comments and retweets to justify the quality of the products or account for service delivery. The notion is to create a standardized platform where people can interact and carry out business simultaneously. Marketers strive to reach out to potential consumers by creating appealing adverts on their social media accounts. Besides, small businesses encourage the creation of fan pages to receive insights from customers. The exchange of information through tweets allows room for product or service enhancement. Therefore, companies understand consumer needs based on the comments left via their Facebook fan pages. Marketing, however, is a field that adjusts with the help of social media platforms.

\section{REFERENCES}

[1]Tritama, H. B., \& Tarigan, R. E. (2016). The effect of social media to the brand awareness of a product of a company. CommIT (Communication and Information Technology) Journal, 10 (1), 9-14.

[2]SmartInsights. (2019, June 10). Increasing Brand Awareness is Main Goal for social media Strategies. Social Media Marketing. https://www.smartinsights.com/social-mediamarketing/increasing-brand-awareness-main-goalfor-social-media-strategies/.

[3]Mosley, M. (2019, Feb 4). How Social Media Increases Brand Awareness. B2C. https://www.business2community.com/socialmedia/how-social-media-increases-brandawareness-02165638. 
[4]Bilgin, Y. (2018). The effect of social media marketing activities on brand awareness, brand image and brand loyalty. Business \& Management Studies: An International Journal, 6 (1), 128-148.

[5]Travelpayouts. (2021, July 5). Ways to Turn Your Website Traffic into Money. Blog. https://blog.travelpayouts.com/en/ways-to-turnyour-website-traffic-into-money/.

[6]Bishop, T. (2017). Website Traffic Behavior that Impacts Total Session Revenue. Ezoic. https://www.ezoic.com/website-traffic-behaviorimpacts-total-session-revenue/.

[7]Dolega, L., Rowe, F., \& Branagan, E. (2021). Going digital? The impact of social media marketing on retail website traffic, orders and sales. Journal of Retailing and Consumer Services, 60, 102501.

[8]Huang, T. K., Liao, C. Y., Wang, Y. T., \& Lin, K. Y. (2018, January). How does social media interactivity affect brand loyalty?. In Proceedings of the 51st Hawaii international conference on system sciences.

[9]Rayat, A., Rayat, M., \& Rayat, L. (2017). The impact of social media marketing on brand loyalty. Annals of Applied Sport Science, 5(1), 73-80.

[10]Salamader, G. (2021). Improve Brand Loyalty Through Social Media Marketing. Eclincher. Retrieved from: https://eclincher.com/improvebrand-loyalty-through-social-media-marketing/.

[11]Newberry, C. (2021, Feb 4). Social Media Customer Service Tips and Tools to Do it Right. Hootsuite. Retrieved from: https://blog.hootsuite.com/socialmedia-customer-service/.

[12]Barnhart, B. (2021, May 12). How to Stop Brands Handle Social Media Customer Service and Support. Sproutsocial. Retrieved from: https://sproutsocial.com/insights/social-customercare/

[13]McCall, K. (2021, Feb 24). What You Can Learn from Wendy's Social Media Strategy. RivalIQ. Retrieved from: https://www.rivaliq.com/blog/wendys-socialmedia-strategy/.

[14]Stone, K. (2021, October 19). Best Practice for Providing Social Media Customer Service. GetVoip.

https://getvoip.com/blog/2020/11/16/social-mediacustomer-service/.

[15]Perdue, D. J. (2010). Social media marketing: Gaining a competitive advantage by reaching the masses.
[16]Zhang, K., \& Sarvary, M. (2011). Social media competition: Differentiation with user-generated content. Marketing Science, 47, 48.

[17]Hanusch, F., \& Tandoc Jr, E. C. (2019). Comments, analytics, and social media: The impact of audience feedback on journalists' market orientation. Journalism, 20 (6), 695-713. 